\title{
EDITORIAL
}

\section{HOW TO REFUSE RESEARCH FROM THE RUINS OF ITS OWN PRODUCTION}

\section{Christian Ulrik Andersen \& Geoff Cox}

APRJA Volume 10, Issue 1, 2021

ISSN 2245-7755

CC license: 'Attribution-NonCommercial-ShareAlike'. 
Writing in 1965, Mario Tronti's claim was that the greatest power of the working class is refusal: the refusal of work, the refusal of capitalist development, and the refusal to bargain within a capitalist framework.

A prerequisite of this process of transition is political organisation, the party, with its demand for total power. In the intervening period there is the refusal - collective, mass, expressed in passive forms - of the workers to expose themselves as "a class against capital" without that organisation of their own, without that total demand for power. The working class does what it is. But it is, at one and the same time, the articulation of capital, and its dissolution.

One can see how this "strategy of refusal" has been utilised in all sorts of instances by social movements, but how does this play out in the context of wider struggles over autonomy today - not just in terms of labour power and class struggles; but also intersectional feminism and queer politics; race and decolonialism, geopolitics, populism, environmental concerns; and the current pandemic? In what ways does a refusal of production manifest itself in contemporary artistic, political, social, cultural, or other movements? And, how might a refusal of certain forms of production come together with a politics of care and "social closeness"?

This publication presents the outcome of an online workshop (organized by Digital Aesthetics Research Centre, Aarhus University; Centre for the Study of the Networked Image, London South Bank University; and transmediale festival, Berlin) with the participation of nine different groups, selected on the basis of an open call (Autumn 2020), and located at different geographical locations, some inside and some outside academia. Each group has worked independently, but has also taken part in a shared mailing list, creating a common list of references, and produced a newspaper as part of the transmediale festival 'almanac' (for Summer 2021). Each in their own way, they have been discussing strategies of refusal, and how these might relate to hegemonic practices of research and its infrastructures.

Perhaps our starting point should be to quote an essay we share our title with, Eve Tuck and K. Wayne Yang's "R-Words: Refusing Research" that operated as inspiration for many of the contributors.

How do we learn from and respect the wisdom and desires in the stories that we (over)hear, while refusing to portray/betray them to the spectacle of the settler colonial gaze? How do we develop an ethics for research that differentiates between power - which deserves a denuding, indeed petrifying scrutiny - and people? At the same time, as fraught as research is in its complicity with power, it is one of the last places for legitimated inquiry. It is at least still a space that proclaims to care about curiosity. In this essay, we theorize refusal not just as a "no," but as a type of investigation into "what you need to know and what I refuse to write in" [...]. Therefore, we present a refusal to do research, or a refusal within research, as a way of thinking about humanizing researchers.

Refusal is grounded in historical and present conditions, and these are particularly pressed upon us during the pandemic. What might be usefully refused in this context, and in what ways? How might academic autonomy be preserved in the context of capitalist tech development, especially perhaps in the present context of online delivery 
and the need for alternatives to corporate platforms (e.g. Zoom, Teams, Skype, and the like); and how to refuse research itself, in its instrumental form?

In her article "Refusing the Burden", Marloes de Valk examines the commitment of Big Tech to diminish its ecological footprint. The COVID-19 pandemic makes the issues at stake all the more apparent, as platforms like Zoom require particular technologies which exclude older hardware/software (e.g. running Linux). As she points out, one way to "refuse the burden" of ICT is to use technologies as long as possible, but also to not be wasteful in terms of processing loads (e.g. camera off; reducing your "facial footprint" as another researcher put it). The paper begins anecdotally with this small but significant act of refusal, rejecting heavy client-side computation and edge computing. We quote directly from her article:

\section{Edge computing and working from home are no solution to environmental collapse, it simply shifts responsibility away from those corporations with the largest footprint. This shifting of responsibility away from corpora- tions is an old strategy. It privatizes and centralizes (often once public) services, while outsourcing costs and responsibilities of care and mainte- nance. On a larger scale, it's classic capitalist extraction of value through the exploitation of free labour and resources, and in the context of this paper, it is also greenwashing.}

The point, and indeed the article, is illustrated neatly by making reference to the "Keep America Beautiful" campaign from the 1950s, a cynical attempt by the disposable packaging industry to circumvent legislation to reduce waste. Individual action in this case can be taken to be an effective way to avoid collective responsibility and the roots of the problem - allowing "business as usual". Much the same trick is taking place in many countries during the pandemic where individual choice is marketed as "freedom", whereas the emphasis would be more productively placed not only on creating commons-based practices and state intervention. There needs to be critical attention to network infrastructures and ecologies in its widest sense. This is a political issue that exposes the contradiction at the heart of capitalism itself allowing it to perform as a self-sustaining viral entity attuned to its own destructive tendencies on a planetary scale.

One important question then is how to operate ethically in the ruins of technological progress? In his article "Towards Refusing as a Critical Technical Practice", Gabriel Pereira raises the question of how to address the inherent contradictions in the development of artificial intelligence (drawing on Phil Agre's notion of 'critical technical practices'), and more specifically examining computer vision, and how the development of various forms of algorithmic 'detectors' are opposed by developers who refuse to work in the corporate tech industry. The computer scientist Joseph Redmon, creator of the widely-used Computer Vision library YOLO, is one example of this. In 2020, he announced that he would no longer be developing the algorithm he created, and explains why:

But maybe a better question is: "What are we going to do with these detectors [Computer Vision algorithms] now that we have them?" A lot of the people doing this research are at Google and Facebook. I guess at least we know the technology is in good hands and definitely won't be used to harvest your personal information and sell it to [...] wait, you're saying that's exactly what it will be used for?? Oh. Well the other 
people heavily funding vision research are the military and they've never done anything horrible like killing lots of people with new technology oh wait...

Pereira draws our attention to how this statement is "crowned by a footnote, which states: 'The author is funded by the Office of Naval Research and Google." In other words,

the conceptualization of hegemony enables thinking of our practice as part of wider struggles for re-constituting these systems. The notion of refusing departs from understanding that counterhegemonic struggles are responses constructed in the interstices of hegemonic forms. That is, even though we may try to re-imagine computer vision, we're still located in relation to this dominant system.

To clarify, he quotes Raymond Williams:

It can be persuasively argued that all or nearly all initiatives and contributions, even when they take on manifestly alternative or oppositional forms, are in practice tied to the hegemonic: that the dominant culture, so to say, at once produces and limits its own forms of counter-culture.

Pereira speculates on the possibilities of a "disobedient gaze" and points to how hegemonies of vision - of what is visible and how it is seen; or, "a particular way of seeing that operates under the goal of identifying and naming, classifying and quantifying, and generally organizing the visual world" works not only at the level of perception, but also in social interaction, the organization of labour, the classification of data, computation and thinking, and so forth (what he calls the 'stack' of computer vision).

Hegemonies as a form of 'common sense', difficult as they are to break from or refuse, are in this way a wider characteristic of "capitalist realism" (taken from the writings of Mark Fisher), which,

as I understand it cannot be confined to art or to the quasi-propagandistic way in which advertising functions. It is more like a pervasive atmosphere, conditioning not only the production of culture but also the regulation of work and education, and acting as a kind of invisible barrier constraining thought and action.

This is made further evident in the article "Towards the Operative Objects of Post-Capitalism" in which Dusan Cotoras, Joaquín Zerené and Diego Gómez-Venegas connect contemporary protests in Chile to how refusal has been regulated in the country's social and cultural history tied, as it is, to socio-cybernetics and the exemplary case of Project Cybersyn. Also speculating on how to relate to capitalist realism and its hegemonic form of control, they argue for a need to embrace the transformations of the country's history: a more radical uncertainty of things - as in their case, the uncertainty of a "theory-fiction" that connects disparate fragments of the specific history and what they refer to as "uncertain objects",

that is, entities defined by multiplicity, whose borders are so transparent, and whose lengths and movements are so unpredictable, that hegemonic research - as an enterprise consolidated with the rise of capitalist realism [...] - tends to avoid, or rather to fight them. On the contrary, we argue that tracing and identifying these objects constitutes in effect, perhaps today 
more than ever, an urgent act of refusal. [...] Therefore, our approach implies embracing radical uncertainty; that is, by refusing the procedures by which objects of interest have been traditionally characterized - serving the analysis and deployment of the historical course of capitalism - allowing instead the operations beneath the aforementioned cloth to become apparent.

Rather than uncertainty leading to what they call a "negative space [...] governed by a cynicism", they suggest uncertainty as a "reservoir energy" that makes possible transformative processes.

Living in transformation and uncertainty might indeed take different forms. In her study of post-industrial young adulthood and "coming of age in the mood economy" (based on numerous interviews with young working-class men and women in the United States), Jennifer M. Silva has showed how neoliberalism forms a kind of subjectivity that (in the words of Fisher, a common reference, suggested in their article) "prides itself on its independence from others," And, as Fisher further notes, when speculating on Silva's emphasis on how personal therapy and selfdevelopment has replaced the formation of a common 'class consciousness' as a generator of change and happiness:

\section{Where consciousness-raising pointed to impersonal and collective structures - structures that capitalist and patriarchal ideology obscures - neoliberalism sees only individuals, choices and personal responsibility.}

The point - already familiar from the earlier example of waste disposal - is that consciousness-raising is not about the accumulation of knowledge, but about changing the way we relate to the world in order to transform it. It is, therefore, a multi-nodal productive operation that creates, again in the words of Fisher, "a new subject - a we that is both the agent of struggle and what is struggled for."

Something similar is argued in the article "Enmeshed in the Borders", in which Rosie Hermon rejects cynicism and blanket refusal. She describes some online experiments in alternative arts education as examples of what she calls "para-institutional practice", understood as forms of border dwelling within the ontology of the "pluriverse" drawn from the decolonial theory of Walter Mignolo:
All of us on the planet have arrived at the end of the era of abstract, disembodied universals - of universal universality. Western universalism has the right to coexist in the pluriverse of meaning. Stripped of its pretended universality, Western cosmology would be one of many cosmologies, no longer the one that subsumes and regulates all the others.

For Mignolo, the figure of the "borderdweller" occupies an uncertain social position and transcultural experience. The point is not to argue for an equivalence of the application of decolonial theory derived from South America to alternative arts education projects in the West but to establish the importance of working "beside and beyond" the institution as she puts it. Rather than refusal, the para-institution acknowledges and works with the tensions and compromises that exist in attempting to operate besides and beyond existing art world structures. Might we say the same for the univers(al)ity in all its contradictions (reminding us of the definition of the university as a place of universal knowledge)? 
Academic conventions of knowledge production, even those commons-based, are clearly not immune. The metaphor of "double-blind peer review" is identified as a case in point by MELT (Loren Britton and Isabel Paehr), of the assumption of ablebodied- and mindedness. We quote from their article: "This academic ritual, amidst others, carries with it ableist assumptions of who is (not) part of academic production." Their identification as trans* and disabled researchers"opens up what they refer to as "trans* and crip knowing-making" which "sets in motion transformative material-discursive processes". The reference is to Aimi Hamraie and Kelly Fritsch's "Crip Technoscience Manifesto", quoted here:

\section{As disabled people engaged in disability community, activism, and scholarship, our collective experiences and histories have taught us that we are effective agents of world-building and-dismantling toward more socially just relations. The grounds for social justice and world-remaking, however, are frictioned; technologies, architec- tures, and infrastructures are often designed and implemented without committing to disability as a difference that matters.}

Drawing upon crip technoscience and trans ${ }^{\star}$ feminism, their "Meltionary" ('melting' the idea of the dictionary as a place of authoritative knowledge) is introduced as a way to provide different materials, metaphors and rituals. Refusal is taken to be an important force in this respect, and as they put it, to drive wedges into structures that exclude. For example, they neatly describe an experiment to insert an ice wedge underneath a metal door frame to slow-down the process of its closing, and to question the binary logic of open or shut. Instead they propose nonbinary structures through which the queerness of the universe can be expressed rather than foreclosed. We'd like to extend this queerness to the university and indeed structures for research. For instance, might we reimagine open access (like a doorway) in terms of its assumptions of time and space?

What do we want of refusal, or what does refusal want with us? Tuck and Wang, once more, provide a useful intervention:

One way to think about refusal is how desire can be a framework, mode, and space for refusal. As a framework, desire is a counterlogic to the logics of settler colonialism. [...] As a mode of refusal, desire is a "no" and a "yes."

So how to operate both inside and outside the institutions of research without perpetuating their exclusions? How to conceive of individual and collective autonomy when contributing to an established festival, an institutionalized research workshop, or an academic publication (like this one)?

Such tricky questions are raised in the article "Nothing Re-fused" developed by Kelsey Brod, Katia Schwerzmann, Jordan Sjol, Alexander Strecker, and Kristen Tapson (aka Nothing Happening Here) in which they suggest the presence of a "neo institution", "immune to refusal, while at the same time an expert in extracting labor, time, knowledge, and attention." We as organizers of the workshop and its publications are implicated, of course, but it is worth pointing out that the participants responded in varying ways to this idea. In a survey instigated by Nothing Happening Here to recognise "our debts" to each other - and making reference to Fred Moten and Stefano Harney's notion of "bad debt" where no repayment is possible — they ask "Do you feel you are in debt to transmediale ( $\left.{ }^{\mathrm{TM}}\right)$ ? If so, how?" Responses 
varied from "No, also not even sure what it is as an entity" to "no. I am pissed that transmediale (as the foremost "hot" theory hub in germany) launches calls open to only highly trained researchers, demands a lot of work from them and doesn't pay." Such diverse answers - both yes and no - leave open the question of where the threshold lies that makes an institution the object of refusal or not. Indeed, we might even ask what constitutes an institution to even begin to formulate its refusal; institutional critique has wrestled with this paradox - at once, making visible the social, political, economic, and historical underpinnings of cultural production, and recognising that "criticality" is itself based on particular class, racial, sexual, gender subject positions - all the time prone to their own institutionalisation.

Our anonymised peer review process similarly identified the problem as irresolvable, and we quote extensively (because we like it so much):

In general, I quite like this paper. It raises what are very real and difficult issues around the expectations placed around precarious academics to participate in collective / collegial aspects of academic research environments and settings despite living through conditions (contractual or otherwise) which undermine that being possible. And needless to say, when you have a condition that demands participation but undercuts the participation of many, that ends up reinforcing all kinds of hierarchies and creating barriers to access that would be much better dismantled, usually without intending to.

I like the idea of stitching in writing / thinking as a way to highlight the difficulties in the conditions of academic labor. In a way it reminds me of Silvia Federici's idea that the point of "Wages for Housework" was not to get wages for it per se, but to make the work visible, and thus to struggle over it. There could be some interesting thinking done here about various kinds of academic work that are not visible but are a key component of the social reproduction of collective thinking and academic labor.

Take for instance writing a peer review. Here it's said that peer reviewing is included in the pay of those who have tenured / permanent jobs. Honestly, not really. Even there it's work that it always assumed rather than rewarded in any meaningful way. A book like Kathleen Fitzpatrick's Planned Obsolescence: Publishing, Technology, and the Future of the Academy.

Speaking from my own experience there are vast amounts of editorial labor that are never accounted for or rewarded by the university. For instance, at this point l've spent at least 16 years working in critical / autonomous publishing (including 12 years editing an open access book series with $40+$ titles in it) - but this has never appeared in a single university workload allocation model or been rewarded by my university at all. So why continue doing it? Well, because I do have the privilege of having a relatively stable and secure job and thus I try to spend as much time as I can making space for others to inhabit and do things with as well, precisely because of how difficult conditions are. Does it always work? Definitely not, but I keep working at it. So there's also a logic of unpaid labor where that unpaid nature of the labor is a potential (insofar as it's less regulated, tracked 
or managed), particularly when the unpaid labor is oriented to the social reproduction of other forms of being and thinking together.

The institution that pays their wage is evidently only part of the problem, and we see some similarities with our own situation too as well as the degree to which waged labour relates to the production of value or not. Indeed we reflect on the alienation of academic labour and valorisation processes at the same time reproduce it through hours of extra work in preparing this journal this summer (when we'd rather be on holiday). Besides the question of how research (critique, writing, editing, and so on) should be rewarded or indebted - or, whether and when it is to be considered a collective action or an institutionalised one - the more general question is made clear of how to struggle over the valorisation of our work?

Nothing Happening Here, mindful of this enduring structuring of bad debt in the context of their participation in the research workshop and publication, provocatively state:

You can catch us on the trash heap, but we are not refuse. We refuse to be treated like shit. This isn't a dump, it's a salvage yard. Join us, if you want.

We like this a lot. There is an echo of the montage-work of Walter Benjamin and his appropriation of textual sources as the "rags, the trash", the "ruins of commodity production" (citing "Thesis on the Philosophy of History"). How would we begin to repay the debt we owe these writers and contributors? We decide to refuse to pay back in established terms, and like Benjamin avoid the academic paywall of quotation. In contrast to traditional academic journal writing (and the conventions of peer review as gatekeeper of quality), we cite freely and ignore our own recommended style guide for references. Benjamin, in refusing, and in being refused by academia, asked whether it was indeed possible to subvert cultural apparatuses from within? In Das Passagen-Werk, he explains:

This work has to develop to the highest degree the art of citing without quotation marks. Its theory is intimately related to that of montage.

We should perhaps begin this introduction again, and be more radical in form. But for now the politics of citation, and the various metrics that inform the reputation economy of academia, confirm the commodity-form at work, but we still don't know how to reject it from within its own confines? This is what many of the contributors of this journal have grappled with: how to "refuse research" from the ruins of its own production.

— Aarhus/London, Summer 2021

Thanks to all workshop participants and contributors to the journal for their patience with the process, our peer reviewers for their help, and transmediale for their support. 


\section{Works (partially) cited:}

Agre, Philip E. "Toward a Critical Technical Practice: Lessons Learned in Trying to Reform Al." In Bridging the Great Divide: Social Science, Technical Systems, and Cooperative Work. Edited by Geoff Bowker, Les Gasser, Susan Leigh Star, and Bill Turner. Erlbaum, 1997.

Anon., Peer review/email, May 24, 2021.

Benjamin, Walter. The Arcades Project. Harvard University Press, 2002.

Federici, Sylvia. Wages for Housework. Power of Women Collective and Falling Wall Press, 1975.

Fisher, Mark. K-Punk: The Collected and Unpublished Writings of Mark Fisher. Repeater, 2018.

Fisher, Mark. Capitalist Realism: Is There No Alternative?. Zero Books, 2009.

Fitzpatrick, Kathleen. Planned Obsolescence: Publishing, Technology, and the Future of the Academy. New York University Press, 2011.

Hamraie, Aimi, and Kelly Fritsch. "Crip Technoscience Manifesto." Catalyst: Feminism, Theory, Technoscience 5.1 (2019): 1-33.

Mignolo, Walter. "Foreword: On Pluriversality and Multipolarity" \& "On Pluriversality and Multipolar World Order." In Constructing the Pluriverse. Edited by Bernd Reiter. Duke University Press, 2018.
Harney, Stefano, and Fred Moten. The Undercommons: Fugitive Planning and Black Study. Minor Compositions, 2013.

Redmon, Joseph, and Ali Farhadi. YOLOv3: An Incremental Improvement. ArXiv, 2018. https://arxiv.org/abs/1804.02767.

Silva, Jennifer M. Coming Up Short: Working-Class Adulthood in an Age of Uncertainty. Oxford: Oxford University Press, 2013.

Tronti, Mario. "The Strategy of the Refusal." Operai e Capitale. Einaudi, 1966, 234-252.

Tuck, Eve, and K. Wayne Yang. "R-Words: Refusing Research." Humanizing Research: Decolonizing Qualitative Inquiry With Youth and Communities. Edited by Django Paris and Maisha T. Winn. Sage (2014): 223-47.

Williams, Raymond. Marxism and Literature. Oxford University Press, 1977. 
